\title{
Endocrine Cells of the Colon in Hirschsprung's and Control Children
}

\author{
M.L. Cristina ${ }^{1}$, T. Lehy ${ }^{1}$, N. Voillemot ${ }^{1}$, P. Arhan ${ }^{2}$, D. Pellerin ${ }^{2}$, and S. Bonfils ${ }^{1}$ \\ ${ }^{1}$ Unité de Recherches de Gastroentérologie, INSERM U. 10, Hôpital Bichat, \\ F-75877 Paris Cedex 18, France \\ ${ }^{2}$ Service de Chirurgie et de Physiologie, Hôpital Necker-Enfants Malades, \\ F-75015 Paris, France
}

Virchows Arch. A Path. Anat. and Histol. 377, 287-300 (1978)

In Table 2, page 295, the title of the last column should read GLI/SRIF instead of SRIF/GLI. 